\title{
EPMA Analysis of Corroded Hot-Dip Galvanized Carbon Steel using the "Phase Map Maker” Software
}

Ryota Kamiyama $^{1}$, Peter McSwiggen ${ }^{3}$, Naoki Kato ${ }^{1}$, Shigeru Honda ${ }^{1}$, Norihisa Mori ${ }^{1}$ and Charles Nielsen ${ }^{2}$

1. JEOL Ltd., 1-2 Musashino, 3 Akishima, Tokyo 196-8558 Japan

2. JEOL USA, Inc., 11 Dearborn Road Peabody MA 01960 USA

3. McSwiggen \& Associates, 2855 Anthony Lane, St. Anthony, MN 55418 USA

Scatter diagrams are a very useful technique for structure analysis of materials using EPMA map data. We developed the "Phase Map Maker", an automatic scatter diagram analysis program for the JEOL JXA-8230 / 8530F series EPMA. The "Phase Map Maker" was used in the analysis of hot-dip galvanized carbon steel.

Hot-dip galvanizing is a widely used anti-corrosion technique. There are two beneficial anti-corrosion characteristics of this galvanization process. One is that of a protective coating, in which the zinc layer provides corrosion resistance. Another is that of sacrificial protection, in which the zinc provides a galvanic protection of the iron when iron substrate is exposed locally.

A test piece of hot-dip galvanized steel was treated with a salt spray test. This treatment, according to JIS Z 2371, is a neutral 5\% aqueous sodium chloride solution sprayed 1008 hours at $35^{\circ} \mathrm{C}$. The test pieces from before and after the salt spray test were cut and made into polished cross sections. These samples were analysed and confirmed to have a $\eta$ layer $(\mathrm{Zn})$, a $\zeta$ layer $\left(\mathrm{FeZn}_{13}\right)$ and a $\delta_{1}$ layer $(\mathrm{FeZn} 7)$, which is the general structure of hot-dip galvanized steel [1]. A scatter diagram analysis was applied to element maps from the two test pieces.

Figure 1 shows the analysed result of a sample before salt splay. The results show that the plating layer is divided into two sub-layers, a zinc phase ( $\eta$ layer) and intermetallic compound phase. Quantitative analyses indicate that the intermetallic compound phase is the $\zeta$ layer. Furthermore, the $\delta_{1}$ layer was confirmed from line analyses focusing on the interface of the $\zeta$ layer and substrate. These results show that most of the intermetallic compound is the $\zeta$ layer, while the $\delta_{1}$ layer occurs at the interface with the substrate.

Figure 2 shows the result for the test piece exposed to salt splay. The plating layer has separated into two phases similar to the galvanized test piece, except the top layer of the salt-sprayed sample is an oxide layer (Fig. 2a and 2b). A chemical bonding state analysis was done on this top layer. The Zn-L spectrum of the top layer is consistent with that of the $\mathrm{ZnO}$ standard (Fig. 2c). In addition, quantitative analyses of the layer produced atomic concentrations of $\mathrm{Zn}$ and $\mathrm{O}$ of nearly 1: 1. These results are both consistent with a surface phase of $\mathrm{ZnO}$.

There was no clear difference between the intermetallic compound layer of the salt sprayed, treated sample and that of the untreated sample. On the other hand, it is worth to note that the $\eta$ layer found in the untreated sample disappeared in the treated sample, or the $\eta$ layer has oxidized in the treated sample.

The scatter diagram analysis using "Phase Map Maker" has been found to be useful in the analysis of 
intermetallic compounds in hot-dip galvanized steel.

References:

[1] Y Wakamatsu, H Masumoto, M Yamane, M Onishi and T Shimozaki, Tetsu-to-Hagane Vol. 82 (1996) No. 1 P 75

a)
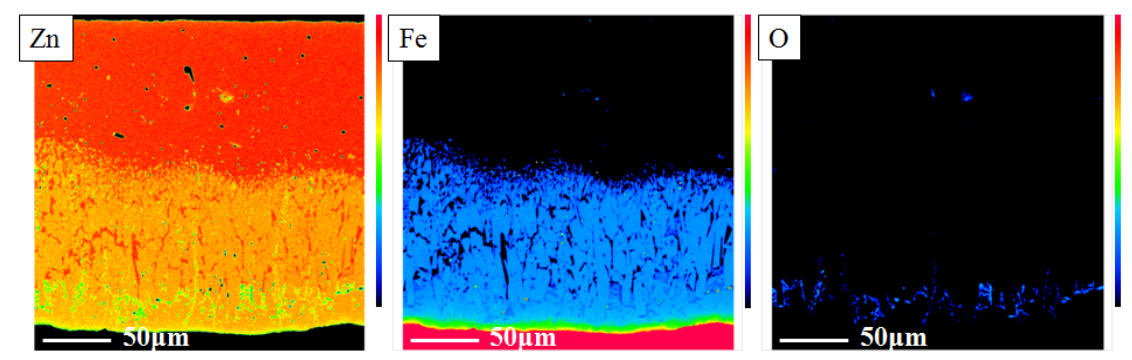

b)

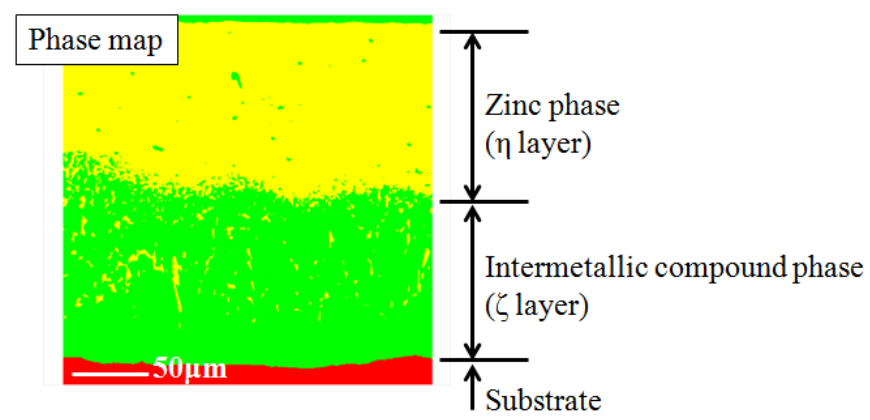

Figure 1. Element maps (a) and phase map obtained by scatter diagram analysis (b) of an untreated galvanized steel sample.

a)

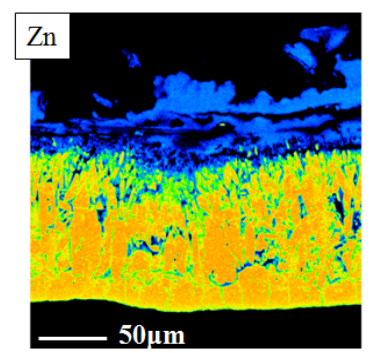

b)

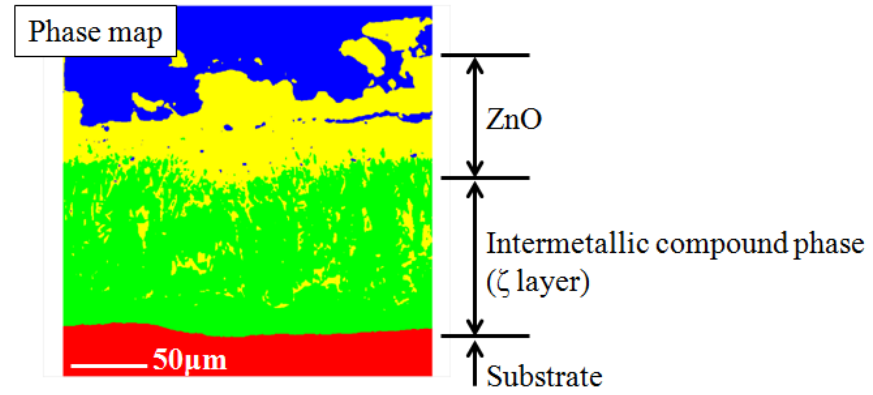

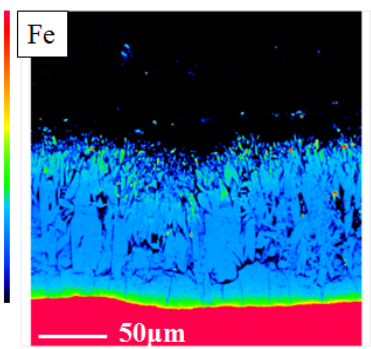

50 um

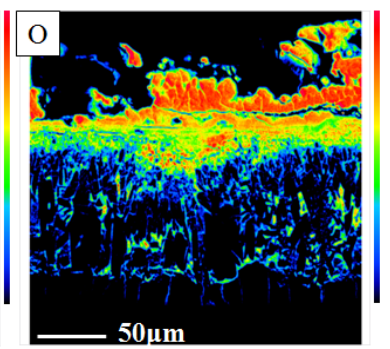

c)

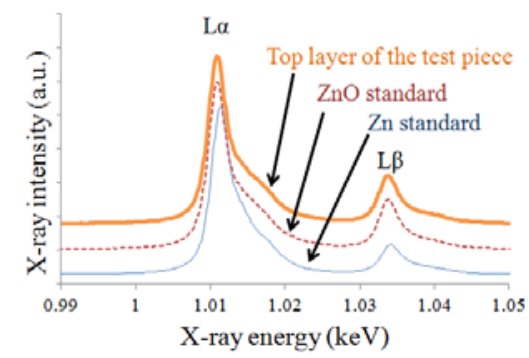

The $\mathrm{Zn}-\mathrm{L}$ spectrum at the top layer

Figure 2. Element maps (a), phase map obtained by scatter diagram analysis (b) and chemical bonding state analysis result (c) of galvanized steel after being treated with a salt spray. 